\title{
Desmoplastic Small Round-cell Tumor: Retrospective Review of Institutional Data and Literature Review
}

\author{
THEJUS JAYAKRISHNAN ${ }^{1}$, RYAN MOLL ${ }^{1}$, ARIEL SANDHU ${ }^{2}$, \\ ANGELA SANGUINO ${ }^{2}$, GURVEEN KAUR ${ }^{3}$ and SHIFENG MAO ${ }^{3}$ \\ ${ }^{1}$ Department of Medicine, Allegheny General Hospital, Pittsburgh, PA, U.S.A.; \\ ${ }^{2}$ Department of Pathology, Allegheny General Hospital, Pittsburgh, PA, U.S.A.; \\ ${ }^{3}$ Allegheny Health Network Cancer Institute, Allegheny General Hospital, Pittsburgh, PA, U.S.A.
}

\begin{abstract}
Background: Desmoplastic small round-cell tumor (DSCRT) in adults is an extremely rare (age-adjusted incidence 0.3 per million) and aggressive sarcoma with limited data for optimal management. Patients and Methods: Retrospective analysis of patients with DSCRT diagnosis (2010-2020) was performed following Institutional Review Board approval. The follow-up period was from pathological diagnosis to the last patient contact. Endpoints were type of response and duration of response. Results: In the current analysis, first-line treatment in all cases was vincristine, anthracycline, and cyclophosphamide alternating with ifosfamide and etoposide (VACIE) with $100 \%$ response for a mean duration of 9.8 (range $=5$ 12) months. Patients received 1-4 subsequent lines of therapy. All patients received temozolomide with irinotecan $(50 \%$ partial response, duration $8-9$ months). Two patients that underwent consolidative cytoreductive surgery with hyperthermic intraperitoneal chemotherapy had a longer survival (30.6 vs. 11.2 months). Patients suffered $100 \%$ mortality with a median survival was 17.8 (range=11.2-30.6) months. Conclusion: While aggressive multimodality treatment is always warranted for DSCRT, the options are limited by the multicentric presentation, short-lived initial response and lack of established subsequent therapy portending a poor prognosis. Consolidative cytoreductive surgery following first-line therapy may improve survival.
\end{abstract}

Desmoplastic small round-cell tumor (DSCRT) in adults is a rare sarcoma predominantly affecting young adults, with an

This article is freely accessible online.

Correspondence to: Shifeng S. Mao, MD, Ph.D., Allegheny Health Network Cancer Institute, Allegheny General Hospital, 320 E North Avenue, Pittsburgh, PA 15212, U.S.A. Tel: +1 4123598836, e-mail: Shifeng.mao@ahn.org

Key Words: Sarcoma, carcinomatosis, metastatic cancer, chemotherapy. age-adjusted incidence of 0.3 per million. It has been three decades since DSCRT was first described as a distinct entity by Gerald and Rosai (1), and our understanding of this disease continues to evolve. For instance, it is well established that the disease predominantly affects the young, with a median age at diagnosis of 22 years (2). Most patients that develop DSCRT harbor the unique chromosomal translocation $\mathrm{t}(11 ; 22)(\mathrm{p} 13: \mathrm{q} 12)$, leading to the fusion of the $\mathrm{N}$-terminal domain of Ewing's sarcoma (EWS) gene to the $C$-terminal domain of Wilms' tumor-suppressor gene (WT1) (3). While aggressive multimodality treatment is always warranted in patients with DSCRT given its aggressive nature, therapeutic options are often limited by the disease extent at presentation, which confers a poor prognosis (3-5). As a result, $60-70 \%$ of patients succumb to DSCRT within 2-3 years despite best care (6).

We describe our institutional experience with this rare and aggressive cancer in the following study. There is a gap of knowledge regarding the response of this cancer to novel systemic therapy agents. We therefore intended to specifically explore the impact of novel molecular targeted therapies and recent advances in surgical techniques, including cytoreductive surgery with hyperthermic intraperitoneal chemotherapy, on DSCRT.

\section{Patients and Methods}

Institutional Review Board approval was obtained (approval number 2019-270), and both the Allegheny Health Network cancer registry as well as the Pathology Department registry were queried to identify patients treated at Allegheny General Hospital for the diagnosis of "desmoplastic small round-cell tumor" over a 10-year duration from 2010-2020. Following the identification of patients, both the current and previous versions of the electronic medical records were queried for data for each case. This included queries through the electronic medical record repository for older cases.

The extracted information included patient demographics (name, age, race and gender), clinical characteristics (radiology and pathology including histology and immunohistochemistry staining), 

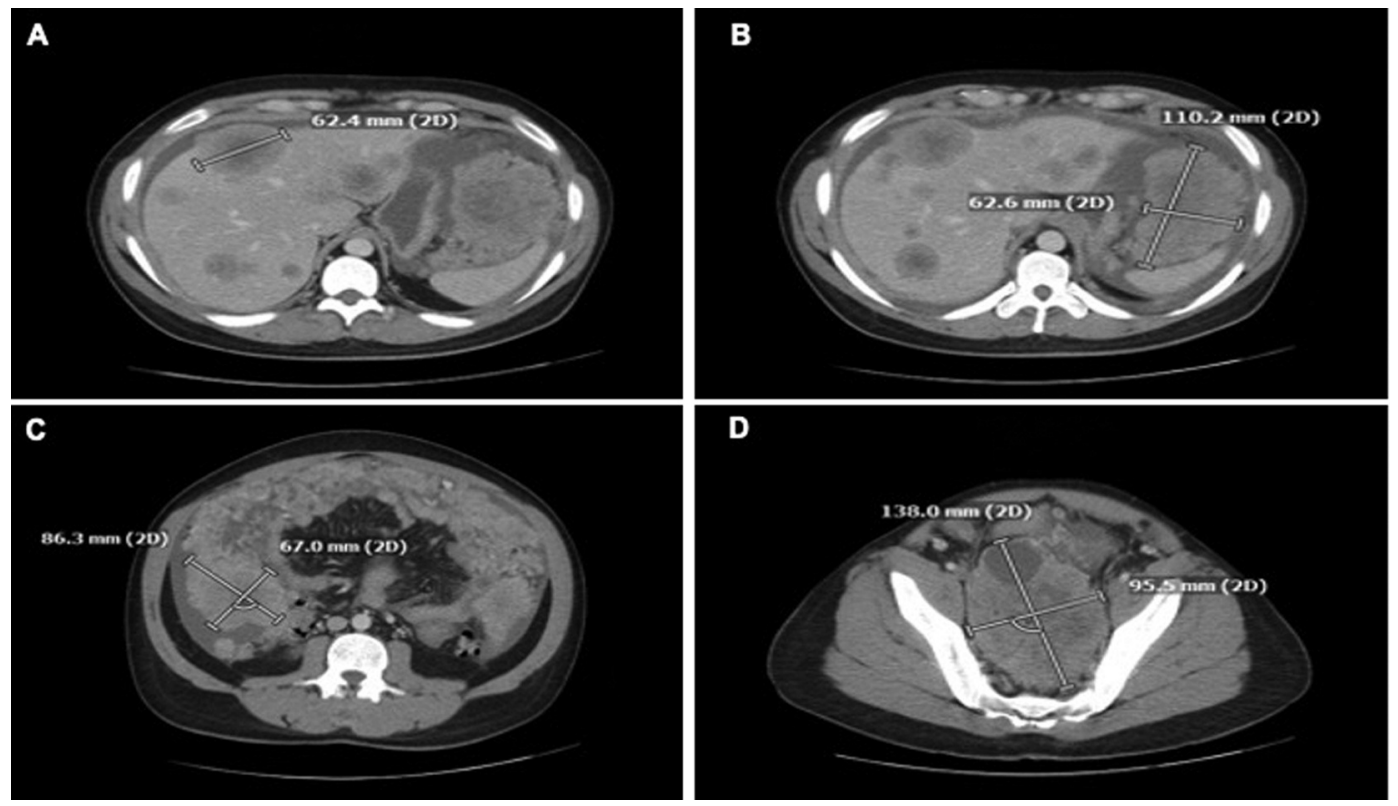

Figure 1. Cross-sectional computed tomographic imaging demonstrating extensive intra-abdominal involvement of tumor with liver metastases (A), and perigastric $(B)$ pericolic $(C)$ and pelvic $(D)$ involvement, as well as carcinomatosis.

treatment history (chemotherapy, surgery) and outcomes (treatment toxicity, recurrence and survival). Names and abbreviations used for chemotherapy and surgery are standard and are defined at the first place of usage. The dosages were according to historically described treatment protocols for sarcoma and adjusted based on response or toxicity (7-15).

The follow-up period spanned from the date of pathological diagnosis to the date of last patient contact or date of death obtained from obituary records. Due to the small dataset/population size, comparative analysis was not performed. Categorical variables are summarized as percentages and continuous variables are summarized as means and ranges.

\section{Results}

Based on the review of records, seven patients were diagnosed with DSCRT at our Institution from 2010 to 2020, and data extraction was possible for four. All patients were White men with a mean age of 29 (range=27-30) years. The mean followup was 24 (range=8-31) months. All patients presented with gastrointestinal symptoms (abdominal distention, pain, nausea and vomiting) and computed tomography imaging demonstrated widespread peritoneal carcinomatosis in all of the patients (Figure 1). Two patients had liver metastases at presentation. Among these four patients, two were in the very high-risk and two in the high-risk categories (Table I).

Fluorescent in situ hybridization in all four cases demonstrated chromosomal translocation $\mathrm{t}(11 ; 22)(\mathrm{p} 13 ; \mathrm{q} 12)$, resulting in fusion of Ewing sarcoma RNA-binding protein 1 (EWSR1) and Wilm's tumor suppressor (WT1) genes. Positive immunohistochemical markers included cytokeratin CAM5.2 and desmin. While there was weak positivity for the neuroendocrine markers' neuron-specific enolase (one patient), cluster of differentiation CD57 and CD56 (one patient) and epithelial membrane antigen (one patient), stains were negative (100\%) for synaptophysin and chromogranin. Representative samples from surgical and cytological DSCRT specimens are demonstrated in Figure 2. Next-generation sequencing analysis was performed in one case. Genomic alterations identified were Ewing sarcoma breakpoint region 1 (EWSR1)-WT1 fusion and Casitas B-lineage Lymphoma (CBL R149Q). Nextgeneration sequencing was attempted in another patient but failed due to insufficient sample.

All patients presented with advanced non-resectable disease and therefore received systemic chemotherapies as outlined in Table I. All patients received combination chemotherapy with vincristine, doxorubicin, cyclophosphamide alternating with ifosfamide and etoposide (VAC-IE) as first line for a mean of 7.5 (range=3-14) cycles, with overall response of $100 \%$ and complete response in two out of the four patients. The mean duration of response was 9.8 (range $=5-12$ ) months.

DSCRT progressed in all patients eventually and they received one to four lines of subsequent therapies. Beyond the VAC-IE regimen in the first line, only the temozolomide plus 
Table I. Treatment course and response of individual patients.

\begin{tabular}{|c|c|c|c|c|c|c|c|}
\hline Case & $\begin{array}{c}\text { Risk } \\
\text { category }\end{array}$ & $\begin{array}{l}\text { Line of } \\
\text { therapy }\end{array}$ & Treatment & Complications & Response & $\begin{array}{l}\text { TTP, } \\
\text { months }\end{array}$ & $\begin{array}{l}\text { Survival, } \\
\text { months }\end{array}$ \\
\hline \multirow[t]{3}{*}{1} & Very high & 1 & VAC+IE & $\begin{array}{l}\text { Dose reductions, bacteremia } \\
\text { Clostridium difficile infection }\end{array}$ & PR & 5.3 & 8.3 \\
\hline & & 2 & TEM-IRI & Clostridium difficile infection & None & 1 & \\
\hline & & 3 & Imatinib & & None & 2 & \\
\hline \multirow[t]{5}{*}{2} & High & 1 & $\begin{array}{l}\text { VAC+IE followed by CRS-HIPEC } \\
\text { followed by VAC+IE }\end{array}$ & Neutropenia mucositis & $\mathrm{CR}$ & 12 & 28 \\
\hline & & 2 & Cyclophosphamide+ topotecan & Thrombocytopenia & NR & 3 & \\
\hline & & 3 & TEM-IRI & & $\mathrm{CR}$ & 9 & \\
\hline & & 4 & Gemcitabine + docetaxel & & None & 3 & \\
\hline & & 5 & Trabectidin & & None & 1 & \\
\hline \multirow[t]{5}{*}{3} & High & 1 & $\begin{array}{l}\text { VAC+IE followed by CRS-HIPEC } \\
\text { followed by VAC+IE }\end{array}$ & Neutropenia, multiple infections & $\mathrm{CR}$ & 12 & 27 \\
\hline & & 2 & CRS & & $\mathrm{CR}$ & 4 & \\
\hline & & 3 & Pazopanib & & None & 2 & \\
\hline & & 4 & Trabectedin & & None & 1 & \\
\hline & & 5 & $\begin{array}{l}\text { TEM-IRI and bevacizumab, } \\
\text { subsequently nivolumab added }\end{array}$ & $\begin{array}{l}\text { Irinotecan discontinued } \\
\text { due to abdominal pain }\end{array}$ & PR & $\begin{array}{c}8 \text { ( } 5 \text { on } \\
\text { nivolumab) }\end{array}$ & \\
\hline \multirow[t]{2}{*}{4} & Very high & 1 & VAC+IE & $\begin{array}{l}\text { Dose reduction due to cytopenia and } \\
\text { retinal hemorrhage, doxorubicin } \\
\text { discontinued cycle } 11\end{array}$ & PR & 11.2 & 15.4 \\
\hline & & 2 & TEM-IRI and temsirolimus & Severe diarrhea after one cycle & None & 4 & \\
\hline
\end{tabular}

CR: Complete response; CRS-HIPEC: cytoreductive surgery with hyperthermic intraperitoneal chemotherapy; NR: no response; PR: partial response; TEM-IRI: temozolomide with irinotecan; TTP: time to progression; VAC+IE: vincristine, anthracycline, and cyclophosphamide alternating with ifosfamide and etoposide. aBased on imaging at initial presentation (24).

irinotecan regimen (TEM-IRI) led to a response, including complete response in one patient and partial response in another, with durations of response of 9 and 8 months, respectively. Other agents used in subsequent lines included cyclophosphamide plus topotecan, gemcitabine plus docetaxel, bevacizumab (in conjunction with TEM-IRI), nivolumab (in conjunction with temozolomide and bevacizumab), pazopanib, trabectedin, temsirolimus and imatinib (Table I).

Among systemic therapies, the VAC-IE regimen resulted in the highest response rate, $100 \%$, followed by the TEMIRI regimen $(50 \%)$. The rest of the subsequent lines of systemic therapy failed to show any measurable and meaningful response (Table II).

Two patients that underwent consolidative cytoreductive surgery with hyperthermic intraperitoneal chemotherapy (CRS-HIPEC) following the initial chemotherapy using the VAC-IE regimen had a longer survival (30.6 vs. 11.2 months). None of the patients received radiation therapy. All patients succumbed to their disease. Overall median survival was 17.8 (range $=11.2-30.6$ ) months.

\section{Discussion}

Presentation and risk stratification. The findings of our study are consistent with historical data - namely that the disease predominantly affects young adults with a male predilection (6). The disease is notorious for presenting with widespread metastases, making it unamenable to definitive surgery, which was also also our experience $(2,4,5)$. It is common for patients to have significant tumor burden upon initial workup, and symptoms may not be apparent until the peritoneal surfaces are extensively infiltrated with tumor (16).

Histologically, tumors are typically composed of small, round, blue cells with hyperchromatic oval nuclei and scant cytoplasm that are arranged in nests, trabeculae, and sheets within a dense, desmoplastic (scarred and fibrous) stroma (see Figure 2). Mitotic figures are frequent, as well as both local and single-cell necrosis. Immunohistochemistry demonstrates epithelial, mesenchymal, and neural differentiation to varying degrees; all tumors show positivity for keratins and epithelial membrane antigen, and show a characteristic dot-like staining pattern for desmin and vimentin, which are mesenchymal markers (17). Neural markers (CD56, neuron-specific enolase, chromogranin, synaptophysin, and S100 protein) may show positivity but were negative in all but one patient in our study.

Due to the morphological overlap of DSCRT with other types of neoplasm, definitive diagnosis is dependent on molecular analysis by cytogenetics and in situ hybridization or reverse transcriptase polymerase chain reaction studies. 

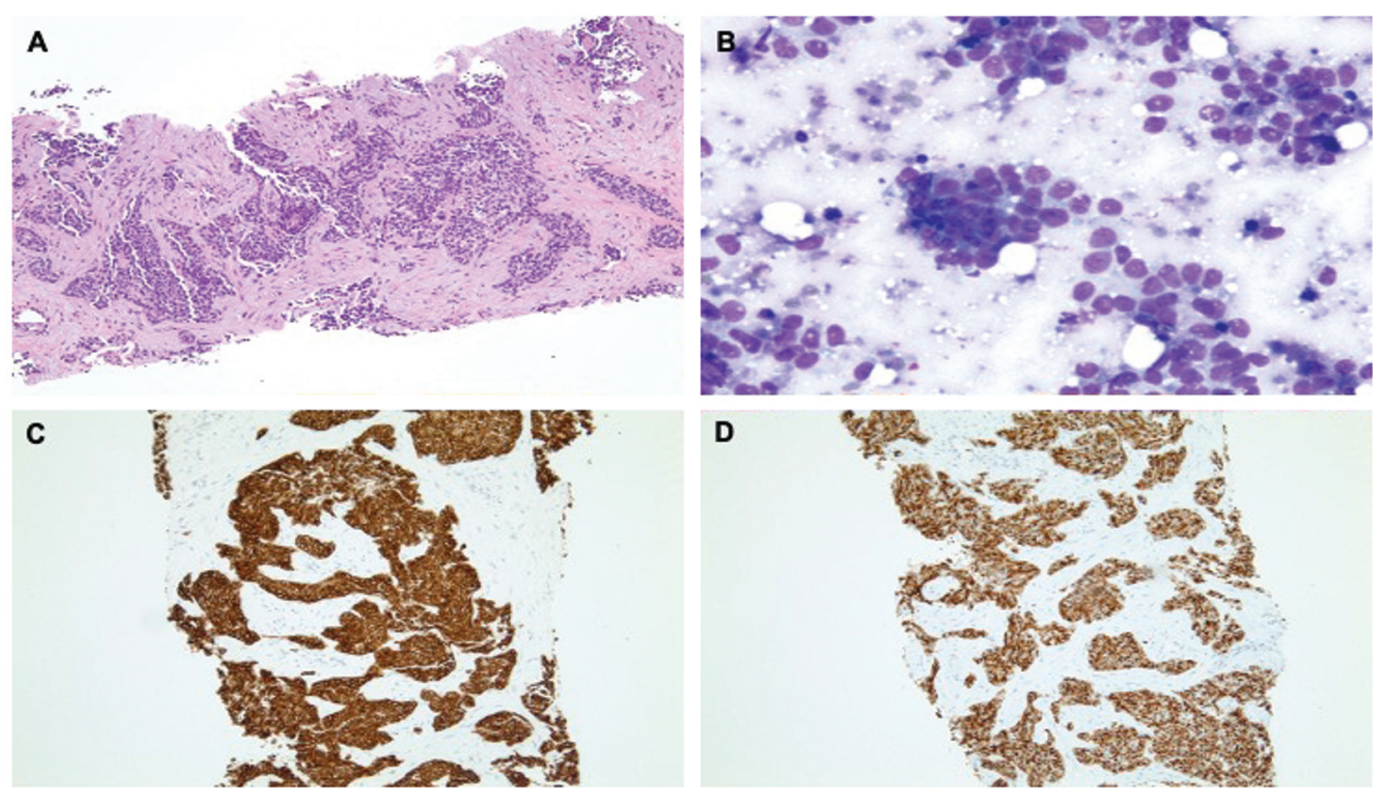

Figure 2. Representative images from histology slides for desmoplastic small round-cell tumor. A: Low-magnification view (10x) B: Highmagnification view (400x) C: Positive staining for cytokeratin CAM5.2. D: Positive staining for desmin.

DSCRT is characterized by the specific $\mathrm{t}(11 ; 22)(\mathrm{p} 13 ; \mathrm{q} 12)$ translocation, with EWSRI-WT1 gene fusion in the majority of cases $(18,19)$. By in situ hybridization, the identification of this characteristic fusion between exon 7 of EWSRl and exon 8 of WTI is therefore crucial in establishing diagnosis (19-21). EWSRI is in fact the most frequent gene to partner with other genes to generate recurrent fusion genes in softtissue neoplasms associated with nonrandom chromosomal translocations (22). Identifying other genes that may assist with risk assessment of this rare disease is important. Moreover, novel liquid biopsy tests for these mutations may offer utility in monitoring patients with known diagnoses (23).

Once diagnosis is established, risk classification for prognostication has been validated based on imaging findings as follows: Intermediate risk: no liver involvement or ascites; high risk: either liver involvement or ascites; very high risk: both liver involvement and ascites. Intermediate-risk patients had a 5 -year survival of $61 \%$ [95\% confidence intervaI $(\mathrm{CI})=40$ $76 \%$ ] versus $16 \%$ (95\% CI=6-29\%) among high-risk patients and $8 \%(95 \% \mathrm{CI}=1-29 \%)$ among very high-risk patients (24). Two of our patients belonged to high-risk category and two others were in the very high-risk category and their mean survivals were 27.5 months and 11.9 months, respectively.

Conventional chemotherapy and efficacy. Optimal treatment of intraabdominal DSRCT (IA DSRCT) involves an aggressive multimodality approach with chemotherapy, surgical resection, and radiation therapy. No single agent has been accepted as the standard chemotherapy. The regimen in
Table II. The outcomes of different treatment approaches for study patients $(n=4)$.

\begin{tabular}{lcrc}
\hline Regimen & $\begin{array}{c}\text { Patients, } \\
\mathrm{n}\end{array}$ & $\begin{array}{c}\text { Response } \\
\text { rate }\end{array}$ & $\begin{array}{c}\text { Median (range) } \\
\text { response, months }\end{array}$ \\
\hline VAC+IE & 4 & $100 \%$ & $9.8(5.3-12.2)$ \\
TEM-IRI & 4 & $50 \%$ & $8.5(1-9)$ \\
CRS+HIPEC & $2 *$ & $100 \%$ & $6.5(5-8)$ \\
Cyclophosphamide+topotecan & 1 & $0 \%$ & $\mathrm{n} / \mathrm{a}$ \\
Gemcitabine+docetaxel & 1 & $0 \%$ & $\mathrm{n} / \mathrm{a}$ \\
Trabectedin & 2 & $0 \%$ & $\mathrm{n} / \mathrm{a}$ \\
Pazopanib & 1 & $0 \%$ & $\mathrm{n} / \mathrm{a}$ \\
Bevacizumab & 1 & $0 \%$ & $\mathrm{n} / \mathrm{a}$ \\
Nivolumab & 1 & $0 \%$ & $\mathrm{n} / \mathrm{a}$ \\
Temsirolimus & 1 & $0 \%$ & $\mathrm{n} / \mathrm{a}$ \\
Imatinib & 1 & $0 \%$ & $\mathrm{n} / \mathrm{a}$ \\
\hline
\end{tabular}

CRS-HIPEC: Cytoreductive surgery with hyperthermic intraperitoneal chemotherapy; TEM-IRI: temozolomide with irinotecan; VAC+IE: vincristine, anthracycline, and cyclophosphamide alternating with ifosfamide and etoposide; *Out of two eligible.

most studies included the chemotherapy protocol for the Ewing family of tumors that emphasizes alkylating agents shown to be effective for small-cell tumors (21). The most common regimen is the P6 protocol or VAC-IE chemotherapy regimen proposed by Kushner et al. (1, 2, 3, and 6 cycles of VAC; 4, 5, 7 cycles of IE) $(7,8)$. Common second-line agents include cyclophosphamide with 
topotecan, TEM-IRI and high-dose ifosfamide. Less common salvage regimens include gemcitabine with docetaxel, cyclophosphamide with vinorelbine, and dacarbazine (8).

Several other regimens have been trialed on an investigational basis and include carboplatin and actinomycin in addition to P6 drugs (5); pazopanib in heavily pre-treated patients $(9,10)$; vinorelbine, cyclophosphamide, and temsirolimus in patients with relapse (25); and eribulin in advanced cases (26). In a study in Germany by Sheet et al. with the largest series of patients with DSRCT enrolled in prospective trials to date, the best outcome was observed with vincristine, dactinomycin, ifosfamide and doxorubicin (VAIA) (5). A modified PAVEP regimen (cyclophosphamide, pirarubicin, etoposide and cisplatin) has been employed by some centers to reduce severe adverse events and to improve the completion rate of chemotherapy $(21,27)$.

In the present study, all patients underwent first-line therapy with VAC-IE or the P6 regimen, with good initial response and variable duration of response $(7,8)$. Two out of the four patients were able to undergo CRS-HIPEC, and this was associated with longer survival, which might also be a reflection of the lower burden of the disease which permitted surgery. TEM-IRI appears to be the second most active regimen following firstline treatment; two out of the four patients responded, including one with complete response. Other systemic therapies, including immunotherapy, anti-angiogenesis agents, and oral tyrosine kinase inhibitors, failed to show any meaningful efficacy but added treatment toxicities. The high mortality from the disease is also universal $(2,4,5)$.

Novel systemic therapy. In the present study, we have described our experience with novel agents involving antivascular endothelial growth factor, multi-kinase inhibitors and mammalian target of rapamycin (mTOR) inhibitors. A limited number of studies have reported the use of these agents in DSRCT, with inconsistent outcomes. A substantial number of DSRCTs overexpress vascular endothelial growth factor receptor-2, and a handful of patients have had clinical responses to sunitinib, sorafenib, or pazopanib. Other biological therapies such as mTOR inhibitors, antiganglioside GD2 antibodies, imatinib, and a combination of insulin-like growth factor-1 with mTOR inhibitors have shown limited success $(8,11)$. Biological agents that have shown effect include anlotinib (8), apatinib (28) and trabectedin (12). In one study, imatinib was used to treat patients with DSRCT after molecular-based selection but failed to show efficacy, similarly to our experience (13). A study by Wedekind et al. found high human leukocyte antigen and cytotoxic T-cell target scores, low programmed death ligand-1 expression and increase in CD56+ natural killer cells in DSRCT samples from diagnosis to recurrence. It was therefore suggested that DSRCT may be amenable to immunotherapies based on human leukocyte antigen and cytotoxic T-cell target scores target scores (29). Their study also demonstrated reduction of these scores at recurrence, reflecting possible immune evasion, but the impact on outcomes is not well elucidated (29). Some have implicated a stem cell hypothesis in DSRCT based on the relative insensitivity of the tumor to high-dose chemotherapy (27). Unlike Ewing sarcoma, CD133+ stem cells have not yet been identified in DSCRT (27). Aggressive chemotherapy followed by stem cell therapy has been proposed but is not supported by evidence to date $(30,31)$.

Role of surgery and radiation therapy. Surgical aspects of the treatment of this disease involve multivisceral resection combined with peritonectomy. Due to peritoneal implantation and the presence of residual tumor tissue after visceral resection, HIPEC with cisplatin is performed as an effective adjunctive therapy $(8,32,33)$. Jordan et al. demonstrated good outcome in patients with limited liver metastases able to undergo complete cytoreduction in the liver (34). In a case report by Cracco et al., a patient with bilobar liver metastases underwent CRS with HIPEC and was tumor-free at 2 years (35). Where surgical therapy is considered, a strategy of neoadjuvant chemotherapy for systemic control followed by surgery for local control might also be tried but experience is limited (21). A tolerable outpatient regimen in these cases includes neoadjuvant vincristine, ifosfamide, dexrazoxane/ doxorubicin, and etoposide. However, HIPEC has not been shown to statistically improve survival (36). Similar findings were observed in other countries such as Canada and USA (6, 30, 37-39). In our study, two out of four patients had disease amenable to CRS-HIPEC and had the longest survival compared to other patients. It is, however, unclear whether the prolonged survival was due to the surgical procedure or to the excellent response (both patients achieved complete response) to first-line chemotherapy, the P6 regimen, which rendered adjuvant CRS-HIPEC possible.

Adjuvant therapy options include radiotherapy (30 Gy, whole abdomen) with or without chemotherapy agents such as irinotecan and temozolomide (16). Although overall survival (OS) may not be affected, radiation therapy may improve outcomes in these patients $(3,33,40-42)$. Radiation is also used for palliation on tumor recurrence (8). In the present study, radiation therapy was not utilized.

Survival and prognostic factors. In rare tumors such as DSCRT, cancer registries can be used to perform pooled analysis of a large number of patients and to assess their trends in treatment and outcomes. In one such study on DSCRT that used the National Cancer Database, 41.2\% (n=200) underwent surgical resection of their primary tumor, chemotherapy was administered to $86.5 \% \quad(n=415)$ of patients and radiation therapy was administered to $13.0 \%(n=63)$ of patients $(37)$. With multimodal therapy, the median OS in DSCRT ranges 
between 24 and 34 months (33). In a French Sarcoma Group study among adult patients, the median OS was 25 months; the 1-, 3- and 5-year OS rates were 90\%, 35\% and 4\%, respectively. Five patients were considered cured after a median disease-free interval of 100 (range=22-139) months. Factors predictive of cure were female sex, median peritoneal carcinomatosis index $<12$, MD Anderson stage I, completeness of cytoreduction score $\mathrm{CC} 0 / 1$ and whole abdomino-pelvic radiation therapy (36). Another National Cancer Database based study showed $69.7 \%$ of patients diagnosed with DSCRT died during the follow-up period, with a median OS of 25.9 (interquartile range $=22.7-27.5$ ) months; 1 -, 3-, and 5-year OS rates were $78.6 \%, 32.3 \%$, and $18.4 \%$, respectively. On multivariable analysis in this study, stage IV disease, and receipt of surgery, chemotherapy or radiation therapy were independently associated with improved OS (37).

In an MD Anderson case series, median OS of 60 months was achieved. After 18 months of follow-up, 20 patients $(62.5 \%)$ had disease recurrence and median disease-free survival was 10 months. The median time to extrahepatic abdominal failure was 19.4 months. Factors affecting time to local progression included liver metastases at diagnosis, and an interval of greater than 5.6 months between diagnosis and HIPEC or greater than 2.1 months between HIPEC and whole abdominal radiation therapy. None of these factors altered OS. Grade 3 or higher toxicities occurred in $84 \%$ of patients (43). In another study, with a median follow-up of 59.9 months, the median survival was 37.7 months, and the median disease-free survival was 15.5 months. The factors predictive of 3 -year OS were the absence of extra-peritoneal metastases, complete surgical resection, postoperative whole abdominal radiation therapy, and postoperative chemotherapy. HIPEC had no impact on OS in their study (32).

Treatment-related toxicity. As the above-mentioned studies show, while patients do respond to therapies, these are often insufficient for long-term benefit and patients also experience high treatment-related toxicity (21). For instance, Pahuja et al. reported complete response to treatment but the patient died of treatment complications (44). In a study by Stiles et al., patients achieved a median OS of 45 (95\% CI=35.1-54.9) months but long-term parenteral nutrition was required in eight patients for a median of 261 (range=37-997) days. Clinically significant long-term complications requiring further surgery included gastroparesis (one patient), small bowel obstruction (three patients) and hemorrhagic cystitis (two patients) (45). Thus, quality of life should be an important consideration in taking care of this patient population.

\section{Conclusion}

DSRCT remains an ominous tumor with poor prognosis. Studies are ongoing to understand the mechanisms of tumor heterogeneity and drug resistance in this tumor type (18). Based on currently available evidence, the best treatment strategy incorporates chemotherapy using the P6 protocol VAC-IE in combination with appropriate surgical and radiation therapy approaches. While novel targeted agents are being used, the results have not been promising. Despite aggressive therapy, outcomes continue to be poor and patient preferences on quality of life should be an important consideration in the decision-making process. This study is limited by its small case number at a single institution and retrospective nature. While prospective clinical trial for such a rare entity can be challenging, sharing experiences in the oncology community through retrospective studies should be valued.

\section{Conflicts of Interest}

No Author has any conflicts of interest in regard to this study.

\section{Authors' Contributions}

Study concept and design: All Authors. Data collection: Thejus Jayakrishnan, Ryan Moll and Ariel Sandhu. Analysis and interpretation of data: Thejus Jayakrishnan, Ryan Moll, Ariel Sandhu, Angela Sanguino and Shifeng Mao. Drafting of the article: Thejus Jayakrishnan, Ryan Moll, Ariel Sandhu, Angela Sanguino and Shifeng Mao. Critical revision of the article for important intellectual content: All Authors. Administrative, technical, or material support: Shifeng Mao.

\section{References}

1 Gerald WL and Rosai J: Case 2. Desmoplastic small cell tumor with divergent differentiation. Pediatr Pathol 9(2): 177-183, 1989. PMID: 2473463. DOI: 10.3109/15513818909022347

2 Morani AC, Bathala TK, Surabhi VR, Yedururi S, Jensen CT, Huh WW, Prasad S and Hayes-Jordan A: Desmoplastic small round cell tumor: Imaging pattern of disease at presentation. AJR Am J Roentgenol 212(3): W45-W54, 2019. PMID: 30673334. DOI: $10.2214 /$ AJR.18.20179

3 Lettieri CK, Garcia-Filion P and Hingorani P: Incidence and outcomes of desmoplastic small round cell tumor: results from the surveillance, epidemiology, and end results database. J Cancer Epidemiol 2014: 680126, 2014. PMID: 25431592. DOI: $10.1155 / 2014 / 680126$

4 Hayes-Jordan A: Cytoreductive surgery followed by hyperthermic intraperitoneal chemotherapy in DSRCT: Progress and pitfalls. Curr Oncol Rep 17(8): 38, 2015. PMID: 26092407. DOI: $10.1007 / \mathrm{s} 11912-015-0461-1$

5 Scheer M, Vokuhl C, Blank B, Hallmen E, von Kalle T, Münter M, Wessalowski R, Hartwig M, Sparber-Sauer M, Schlegel PG, Kramm CM, Kontny U, Spriewald B, Kegel T, Bauer S, Kazanowska B, Niggli F, Ladenstein R, Ljungman G, Jahnukainen K, Fuchs J, Bielack SS, Klingebiel T, Koscielniak $\mathrm{E}$ and Cooperative Weichteilsarkom Studiengruppe [CWS]: Desmoplastic small round cell tumors: Multimodality treatment and new risk factors. Cancer Med 8(2): 527-542, 2019. PMID: 30652419. DOI: 10.1002/cam4.1940 
6 Stiles ZE, Dickson PV, Glazer ES, Murphy AJ, Davidoff AM, Behrman SW, Bishop MW, Martin MG and Deneve JL: Desmoplastic small round cell tumor: A nationwide study of a rare sarcoma. J Surg Oncol 117(8): 1759-1767, 2018. PMID: 29878371. DOI: $10.1002 /$ jso.25071

7 Kushner BH, LaQuaglia MP, Wollner N, Meyers PA, Lindsley KL, Ghavimi F, Merchant TE, Boulad F, Cheung NK, Bonilla MA, Crouch G, Kelleher JF Jr, Steinherz PG and Gerald WL: Desmoplastic small round-cell tumor: prolonged progressionfree survival with aggressive multimodality therapy. J Clin Oncol 14(5): 1526-1531, 1996. PMID: 8622067. DOI: 10.1200/ JCO.1996.14.5.1526

8 Chen HM and Feng G: Use of anlotinib in intra-abdominal desmoplastic small round cell tumors: a case report and literature review. Onco Targets Ther 12: 57-61, 2018. PMID: 30588030. DOI: 10.2147/OTT.S190333

9 Menegaz BA, Cuglievan B, Benson J, Camacho P, LamhamediCherradi SE, Leung $\mathrm{CH}$, Warneke CL, Huh W, Subbiah V, Benjamin RS, Patel S, Daw N, Hayes-Jordan A and Ludwig JA: Clinical activity of pazopanib in patients with advanced desmoplastic small round cell tumor. Oncologist 23(3): 360-366, 2018. PMID: 29212731. DOI: 10.1634/theoncologist.2017-0408

10 Ikeue T, Ohi I, Noguchi S, Fukao A, Terashita S, Horikawa S and Sugita T: Desmoplastic small round cell tumor of the pleura successfully treated with a lower dose of pazopanib. Intern Med 55(17): 2463-2467, 2016. PMID: 27580551. DOI: 10.2169/ internalmedicine. 55.6395

11 Bétrian S, Bergeron C, Blay JY, Bompas E, Cassier PA, Chevallier L, Fayette J, Girodet M, Guillemet C, Le Cesne A, Marec-Berard $\mathrm{P}$, Ray-Coquard I and Chevreau C: Antiangiogenic effects in patients with progressive desmoplastic small round cell tumor: data from the French national registry dedicated to the use of offlabeled targeted therapy in sarcoma (OUTC's). Clin Sarcoma Res 7: 10, 2017. PMID: 28491276. DOI: 10.1186/s13569-017-0076-4

12 Verret B, Honore C, Dumont S, Terrier P, Adam J, Cavalcanti A, Sourrouille I, Klausner G, Ahlenc-Gelas M, Kiavue N, Domitrescu G, El Amarti L, Mir O and Le Cesne A: Trabectedin in advanced desmoplastic round cell tumors: a retrospective single-center series. Anticancer Drugs 28(1): 116-119, 2017 PMID: 27782906. DOI: 10.1097/CAD.0000000000000435

13 De Sanctis R, Bertuzzi A, Bisogno G, Carli M, Ferrari A, Comandone A and Santoro A: Imatinib mesylate in desmoplastic small round cell tumors. Future Oncol 13(14): 1233-1237, 2017. PMID: 28589771. DOI: 10.2217/fon-2016-0305

14 Palmerini E, Jones RL, Setola E, Picci P, Marchesi E, Luksch R, Grignani G, Cesari M, Longhi A, Abate ME, Paioli A, Szucs Z, D'ambrosio L, Scotlandi K, Fagioli F, Asaftei S and Ferrari S: Irinotecan and temozolomide in recurrent Ewing sarcoma: an analysis in 51 adult and pediatric patients. Acta Oncol 57(7): 958964, 2018. PMID: 29533113. DOI: 10.1080/0284186X.2018. 1449250

15 NCCN Guidelines, Soft Tissue Sarcoma, Version 2.2021. Available at: https://www.nccn.org/professionals/physician_gls/ pdf/sarcoma.pdf [Last accessed on July 2, 2021]

16 Hayes-Jordan A, LaQuaglia MP and Modak S: Management of desmoplastic small round cell tumor. Semin Pediatr Surg 25(5): 299-304, 2016. PMID: 27955733. DOI: 10.1053/j.sempedsurg. 2016.09.005

17 Lae ME, Roche PC, Jin L, Lloyd RV and Nascimento AG: Desmoplastic small round cell tumor: a clinicopathologic, immunohistochemical, and molecular study of 32 tumors. Am J Surg Pathol 26(7): 823-835, 2002. PMID: 12131150. DOI: 10.1097/00000478-200207000-00001

18 Devecchi A, De Cecco L, Dugo M, Penso D, Dagrada G, Brich S, Stacchiotti S, Sensi M, Canevari S and Pilotti S: The genomics of desmoplastic small round cell tumor reveals the deregulation of genes related to DNA damage response, epithelial-mesenchymal transition, and immune response. Cancer Commun (Lond) 38(1): 70, 2018. PMID: 30486883. DOI: 10.1186/s40880-018-0339-3

19 Thway K, Noujaim J, Zaidi S, Miah AB, Benson C, Messiou C, Jones RL and Fisher C: Desmoplastic small round cell tumor: Pathology, genetics, and potential therapeutic strategies. Int $\mathbf{J}$ Surg Pathol 24(8): 672-684, 2016. PMID: 27621277. DOI: $10.1177 / 1066896916668637$

20 Hatanaka KC, Takakuwa E, Hatanaka Y, Suzuki A, IIzuka S, Tsushima N, Mitsuhashi T, Sugita S, Homma A, Morinaga S, Hashegawa T and Matsuno Y: Desmoplastic small round cell tumor of the parotid gland-report of a rare case and a review of the literature. Diagn Pathol 14(1): 43, 2019. PMID: 31103034. DOI: 10.1186/s13000-019-0825-1

21 Ambar NBD, de Seixas Alves MT, Lederman HM, Abib S, Duarte $\mathrm{AAB}$ and Caran EM: Irinotecan and vincristine for the treatment of refractory desmoplastic small round cell tumor in a developing country: a case report. J Med Case Rep 13(1): 77, 2019. PMID: 30851735. DOI: 10.1186/s13256-019-1985-z

22 Thway K and Fisher C: Mesenchymal tumors with EWSR1 gene rearrangements. Surg Pathol Clin 12(1): 165-190, 2019. PMID: 30709442. DOI: 10.1016/j.path.2018.10.007

23 Ferreira EN, Barros BD, de Souza JE, Almeida RV, Torrezan GT, Garcia S, Krepischi AC, Mello CA, Cunha IW, Pinto CA, Soares FA, Dias-Neto E, Lopes A, de Souza SJ and Carraro DM: A genomic case study of desmoplastic small round cell tumor: comprehensive analysis reveals insights into potential therapeutic targets and development of a monitoring tool for a rare and aggressive disease. Hum Genomics 10(1): 36, 2016. PMID: 27863505. DOI: 10.1186/s40246-016-0092-0

24 Saltsman JA 3rd, Price AP, Goldman DA, Hammond WJ, Danzer E, Magnan H, Slotkin E, Tap WD, Heaton TE, Modak S and LaQuaglia MP: A novel image-based system for risk stratification in patients with desmoplastic small round cell tumor. J Pediatr Surg 55(3): 376-380, 2020. PMID: 29605262. DOI: $10.1016 /$ j.jpedsurg.2018.02.068

25 Tarek N, Hayes-Jordan A, Salvador L, McAleer MF, Herzog CE and Huh WW: Recurrent desmoplastic small round cell tumor responding to an mTOR inhibitor containing regimen. Pediatr Blood Cancer 65(1), 2018. PMID: 28941151. DOI: $10.1002 / \mathrm{pbc} .26768$

26 Emambux S, Kind M, Le Loarer F, Toulmonde M, Stoeckle E and Italiano A: Clinical activity of eribulin in advanced desmoplastic small round-cell tumor. Anticancer Drugs 28(9): 1053-1055, 2017. PMID: 28863036. DOI: 10.1097/CAD.00 00000000000536

27 Bulbul A, Fahy BN, Xiu J, Rashad S, Mustafa A, Husain H and Hayes-Jordan A: Desmoplastic small round blue cell tumor: A review of treatment and potential therapeutic genomic alterations. Sarcoma 2017: 1278268, 2017. PMID: 29225486. DOI: $10.1155 / 2017 / 1278268$

28 Shi C, Feng Y, Zhang LC, Ding DY, Yan MY and Pan L: Effective treatment of apatinib in desmoplastic small round cell 
tumor: a case report and literature review. BMC Cancer 18(1): 338, 2018. PMID: 29587657. DOI: 10.1186/s12885-018-4135-x

29 Wedekind MF, Haworth KB, Arnold M, Stanek JR, Lee D and Cripe TP: Immune profiles of desmoplastic small round cell tumor and synovial sarcoma suggest different immunotherapeutic susceptibility upfront compared to relapse specimens. Pediatr Blood Cancer 65(11): e27313, 2018. PMID: 30015384. DOI: $10.1002 /$ pbc. 27313

30 Bailey K, Roth M, Weiser D and Gill J: High-dose chemotherapy with stem cell rescue in desmoplastic small round cell tumor: A single-institution experience and review of the literature. Sarcoma 2018: 1948093, 2018. PMID: 29853779. DOI: $10.1155 / 2018 / 1948093$

31 Forlenza CJ, Kushner BH, Kernan N, Boulad F, Magnan H, Wexler L, Wolden SL, LaQuaglia MP and Modak S: Myeloablative chemotherapy with autologous stem cell transplant for desmoplastic small round cell tumor. Sarcoma 2015: 269197, 2015. PMID: 25945075. DOI: 10.1155/2015/269197

32 Honoré C, Atallah V, Mir O, Orbach D, Ferron G, LePéchoux C, Delhorme JB, Philippe-Chomette P, Sarnacki S, Msika S, Terrier P, Glehen O, Martelli H, Minard-Colin V, Bertucci F, Blay JY, Bonvalot S, Elias D, LeCesne A, Sargos P and French Network for Rare Peritoneal Malignancies (RENAPE), French Pediatric Cancer Society (SFCE), French Reference Network in Sarcoma Pathology (RRePS) French Sarcoma Clinical Network (NETSARC): Abdominal desmoplastic small round cell tumor without extraperitoneal metastases: Is there a benefit for HIPEC after macroscopically complete cytoreductive surgery? PLoS One 12(2): e0171639, 2017. PMID: 28234908. DOI: 10.1371/ journal.pone.0171639

33 Zhang S, Zhang Y, Yu YH and Li J: Results of multimodal treatment for desmoplastic small round cell tumor of the abdomen and pelvis. Int J Clin Exp Med 8(6): 9658-9666, 2015. PMID: 26309640.

34 Hayes-Jordan AA, Coakley BA, Green HL, Xiao L, Fournier KF, Herzog CE, Ludwig JA, McAleer MF, Anderson PM and Huh WW: Desmoplastic small round cell tumor treated with cytoreductive surgery and hyperthermic intraperitoneal chemotherapy: results of a phase 2 trial. Ann Surg Oncol 25(4): 872-877, 2018. PMID: 29383611. DOI: $10.1245 /$ s10434-018-6333-9

35 Cracco A, Roy M and Simpfendorfer CH: Cytoreductive surgery and hyperthermic intraperitoneal chemotherapy combined with two-stage hepatectomy for multiple and bilobar desmoplastic small round cell tumor liver metastases. J Gastrointest Oncol 8(4): E60-E64, 2017. PMID: 28890830. DOI: 10.21037/jgo.2017.07.07

36 Honoré C, Delhorme JB, Nassif E, Faron M, Ferron G, Bompas E, Glehen O, Italiano A, Bertucci F, Orbach D, Pocard M, Quenet F, Blay JY, Carrere S, Chevreau C, Mir O, Le Cesne A and French Network for Rare Peritoneal Malignancies (RENAPE), French Sarcoma Clinical Network (NETSARC): Can we cure patients with abdominal Desmoplastic Small Round Cell Tumor? Results of a retrospective multicentric study on 100 patients. Surg Oncol 29: 107-112, 2019. PMID: 31196472. DOI: $10.1016 /$ j.suronc.2019.04.002

37 Gani F, Goel U, Canner JK, Meyer CF and Johnston FM: A national analysis of patterns of care and outcomes for adults diagnosed with desmoplastic small round cell tumors in the United States. J Surg Oncol 119(7): 880-886, 2019. PMID: 30844086. DOI: $10.1002 /$ jso.25426
38 Angarita FA, Hassan S, Cannell AJ, Dickson BC, Gladdy RA, Swallow CJ, Gupta A, Blackstein ME and McCart JA: Clinical features and outcomes of 20 patients with abdominopelvic desmoplastic small round cell tumor. Eur J Surg Oncol 43(2): 423431, 2017. PMID: 27890349. DOI: 10.1016/j.ejso.2016.08.017

39 Tang Y, Song H, Bao Y and Zhi Y: Multimodal treatment of abdominal and pelvic desmoplastic small round cell tumor with relative good prognosis. Int J Surg 16(Pt A): 49-54, 2015. PMID: 25743388. DOI: 10.1016/j.ijsu.2015.02.015

40 Subbiah V, Lamhamedi-Cherradi SE, Cuglievan B, Menegaz BA, Camacho P, Huh W, Ramamoorthy V, Anderson PM, Pollock RE, Lev DC, Qiao W, McAleer MF, Benjamin RS, Patel S, Herzog CE, Daw NC, Feig BW, Lazar AJ, Hayes-Jordan A and Ludwig JA: Multimodality treatment of desmoplastic small round cell tumor: Chemotherapy and complete cytoreductive surgery improve patient survival. Clin Cancer Res 24(19): 48654873, 2018. PMID: 29871905. DOI: 10.1158/1078-0432.CCR$18-0202$

41 Atallah V, Honore C, Orbach D, Helfre S, Ducassou A, Thomas L, Levitchi MB, Mervoyer A, Naji S, Dupin C, Bosco-Levy PJ, Philippe-Chomette P, Kantor G, Henriques de Figueiredo B, Sunyach MP and Sargos P: Role of adjuvant radiation therapy after surgery for abdominal desmoplastic small round cell tumors. Int J Radiat Oncol Biol Phys 95(4): 1244-1253, 2016. PMID: 27354131. DOI: 10.1016/j.ijrobp.2016.02.046

42 Zhang S, Zhang Y, Yu YH and Li J: Complete response of giant desmoplastic small round cell tumor treated with chemoradiotherapy: A case report. Oncol Lett 11(2): 1069-1072, 2016. PMID: 26893693. DOI: 10.3892/ol.2015.4024

43 Osborne EM, Briere TM, Hayes-Jordan A, Levy LB, Huh WW, Mahajan A, Anderson P and McAleer MF: Survival and toxicity following sequential multimodality treatment including whole abdominopelvic radiotherapy for patients with desmoplastic small round cell tumor. Radiother Oncol 119(1): 40-44, 2016. PMID: 26527430. DOI: 10.1016/j.radonc.2015.10.016

44 Pahuja AK and Mundodan MS: Whole abdominopelvic radiotherapy in desmoplastic small round cell tumour of abdomen: a challenge for radiation oncologists. BMJ Case Rep 2018: bcr2018224838, 2018. PMID: 29866686. DOI: 10.1136/bcr-2018-224838

45 Stiles ZE, Murphy AJ, Anghelescu DL, Brown CL, Davidoff AM, Dickson PV, Glazer ES, Bishop MW, Furman WL, Pappo AS, Lucas JT Jr and Deneve JL: Desmoplastic small round cell tumor: Long-term complications after cytoreduction and hyperthermic intraperitoneal chemotherapy. Ann Surg Oncol 27(1): 171-178, 2020. PMID: 30963398. DOI: 10.1245/s10434019-07339-2 